\title{
Citizenship Education in the Kingdom of Saudi Arabia: History and Current Instructional Approaches
}

Badr Abdullah Alharbi*

School of Education, Hail University, Saudi Arabia

Corresponding author: Badr Abdullah Alharbi, E-mail: ba.alharbi@uoh.edu.sa

\begin{tabular}{l} 
ARTICLE INFO \\
\hline Received: July 20, 2017 \\
Accepted: October 22, 2017 \\
Published: October 31, 2017 \\
Volume: $5 \quad$ Issue: 4 \\
\hline
\end{tabular}

Conflicts of interest: None Funding: None

\begin{abstract}
This review article attempts to review current studies related to Citizenship Education (CE) in order to shed light on the provisions of citizenship education in the Kingdom of Saudi Arabia (KSA). The review examines the significance of CE in the KSA. It also explores the history of CE in the KSA followed by its national identity, as this too, affects the nature of the CE offered in the country. Then the article identifies and explores the implementation of CE in the KSA. In addition, the article discusses the approaches of introducing Citizenship Education in the KSA, its content and implementation. It can be argued that Islam has played a crucial role in shaping Saudi citizens' private and national identities and their national values. The study also found that CE in Saudi Arabia faces multiple challenges. It emphasizes citizens' responsibilities, duties, identity formation, and obedience towards the system and how one can achieve them. It also appears that promoting freedom, equality, fairness, freedom of expression and participation in the decision making process is poorly addressed. Moreover, lack of teaching aids and lack of specialist teachers and training are some major challenges to implement CE in the KSA. The article ends by drawing some conclusions.
\end{abstract}

Key words: Citizenship Education, Pedagogy, Content, Teaching Approaches

\section{INTRODUCTION}

There has been a growing interest in citizenship education (CE) since the early 1990s, as Lee (2004) notes: "developing good citizenship has been a continuing educational concern worldwide" (p.137). This interest in CE in Western countries has been fostered by huge transformations, including the challenges of increasingly multicultural societies, the alleged breakdown of moral fabric, the democratic deficit, the decline of volunteerism in community activities and also the changing role of women (Mellor \& Prior 2004; Wilkins 2003). CE is seen as a means by which we can equip young students with the knowledge, skills and understanding to play a decisive role in society. Teaching individual values, knowledge and skills helps in building strong individuals capable of taking an interest in contemporary issues and being involved in discussion and debate (Qualifications and Curriculum Authority, 2007).

Unlike the Western context, CE in some Arab countries has only been introduced into the educational arena since the beginning of the current decade (Almaamari, 2009). Many conferences and seminars about $\mathrm{CE}$ have been held at national and regional levels. For instance, in the Gulf region, where the KSA is located, there has been a growing interest in $\mathrm{CE}$ among policymakers, academics, the media and educational stakeholders (Alhabib, 2010). During the first decade of the $21^{\text {st }}$ century, three major conferences on CE were organized in three Gulf states: (1) in Bahrain from February $24^{\text {th }}$ to $25^{\text {th }}, 2008$ (under the title: The culture of citizenship in the countries of the Gulf Cooperation Council), (2) in the UAE capital, Abu Dhabi, from March $31^{\text {st }}$ to April $4^{\text {th }}, 2008$ (under the title: Arabian Gulf between conservatism and change) and (3) in Kuwait, from February $21^{\text {st }}$ to $22^{\text {nd }} 2010$ (under the title: Citizenship in Kuwait - Present and Future).

As far as the KSA is concerned, CE was re-introduced into the education system in 1997 in all stages from primary to secondary to provide students with information about the values, principles and characteristics of good citizens. Before that CE was taught in stage 3 and 4 in primary schools and later in secondary schools. This will be discussed in the section of history of CE in the KSA. CE as a subject also aims at educating students in a humanistic manner so that their behaviour and actions are based on sound ethical principles. As a result, it is hoped that students gain sufficient knowledge to enable them to assume responsibility and serve their religion, country and society (Mokhtar, 2007).

The need for CE in the KSA is indisputable because of the substantial economic and social developments that the country has witnessed since the 1970s and 1980s. Before the discovery of oil in 1938, the KSA consisted of scattered tribes with their own customs and territories. Education was then the family's sole responsibility; however, after discovering oil, the government received sufficient income and 
took on the responsibility of providing education to all its citizens. This led to the formation of a national education system, aimed at preparing young people for a different, more urban way of life (Alhuqail, 1994).However, the rapid increase in the income of the Saudi people has caused a number of problems, such as those connected with concerns about excessive materialism. Alturaqe (2000, p.4) explains that "in our contemporary Gulf societies, particularly in the KSA the phenomenon of over materialism has turned into a problem worthy of study and treatment". People in the KSA have become dependent on material goods and accustomed to a certain level of income, which has caused a reluctance to work in particular jobs, like manual work, with many Saudis favouring office work instead. As a result, the government has brought in many foreign labourers to do such jobs, so huge amounts of money are now transferred out of the country by foreign workers, which has in turn weakened the economy, creating further problems. Thus, the government has tried to influence attitudes, reminding people that they should appreciate any kind of work and respect those who do it, as the influx of foreign workers doing manual work has negatively affected the economy (Federation of GCC Chambers, 2007). This impact is demonstrated by the increase in funds transferred annually out of the Kingdom as well as by the rise of unemployment of Saudi Arabians. The Saudi Minister of Labour noted that the unemployment rate rose to about 10.5\% in 2009 from 8.2\% in 2000 (Aljazeera, 2011).

On the social side, Saudi Arabia has not been immune from the recent revolution in technology. There are concerns that the influence of this technology might be negative, especially in relation to younger people who constitute a high percentage of the population. These concerns relate to identity and social traditions, many of which have been challenged by the global media. As a result of technological developments, seven out of ten people in the KSA now have a smart phone (CITC, 2013) which has inevitably influenced relationships and communication between young people within the country and abroad. Social media such as Facebook and Twitter now play a crucial role for the younger Saudi generation who, through this, receive large amounts of information about cultures and events in different parts of the world. According to the sixth Arab Social Media Report conducted by Mohammed Bin Rashid School of Government, the KSA has the highest number of Twitter users in the Arab region reaching 2.4 million users and accounting for over $40 \%$ of all active Twitter users in this region (MBRSG, 2014). At the same time, young Saudi people appear to be engaging less with social and national events, and relationships between neighbours have become weaker than in the past (Alessa, 2009). These changes should be reflected by changes in the education system in order to prepare young people to deal with this new era which made CE substantial to the students.

Interest in $\mathrm{CE}$ in the KSA increased after the events of September 11, 2001, especially with the spread of terrorism in the region and in the KSA. In parallel with this, there is a trend towards increasing political participation leading to municipal elections in towns and cities and national dialogues which centre round such issues as women's rights and the role of young people in KSA society. As a result, there has been an ongoing debate about the role of CE in the education system. The Government held a national conference in Riyadh, the capital of KSA, in 2009 under the title "National affiliation in public education in the KSA". The conference resulted in a number of recommendations being made, such as the need for $\mathrm{CE}$ to be reviewed in state schools and the need to learn from the experiences of other countries in the teaching of CE (Saudi Press Agency, 2009). In addition, the conference recommended that the role of the school in the development of citizenship need to be active. It also advocated to develop effective training programs for teachers to increase their ability and performance with respect to the side of teaching CE (Saudi Press Agency, 2009). Moreover, several empirical studies which assessed the implementation of CE in KSA schools have indicated that $\mathrm{CE}$ faces many challenges in reaching its aims and that there is a need to review the subject and revise the current curriculum in order to be effective (Aldubyan 2013; Almalki 2008; Almaitah 2011; Hanivah 2000). Alabdulkarim and Alnassar (2005) also found that CE in the KSA focuses on the national level and the role of students towards their country and their community, while global issues, citizens' rights, and the international level are neglected.

Politics and religion play a major role in the education system in that they determine the aims and curriculum of education. Many Western countries tend to minimise the importance of religion in political contexts as they believe it has no legitimate political role (Hudson, 2003); however, the situation in the KSA is different since there is a strong relationship between politics and the Islamic religion. The KSA is an Islamic state that has a constitution based on the Holy Quran and the Sunna (traditions of Prophet Muhammad). The supremacy of these two sources of authority is stressed and asserted by the Basic Law of the country which was issued in 1992. Consequently, Islam plays a significant role in shaping the education system.

\section{DEFINITION OF CE}

In general, $\mathrm{CE}$ in schools is important to foster students' knowledge and skills about their rights and responsibilities, moral and social virtues, poverty and wealth, sustainable development, identity, empathy, respect for each other, their identities and so on which are necessary for their active participation in their personal, professional and social life. UNESCO (1998) defines CE as "educating children, from early childhood, to become clear-thinking and enlightened citizens who participate in decisions concerning society." An individual is a part of a society and therefore, teaching human and social issues, law and moral qualities should start from early childhood. When citizens are equipped with knowledge and skills, they can appreciate their rights and responsibilities and can contribute to the betterment of their society and nation. Likewise, the Information Network on Education in Europe (Eurydice) defines CE as: " aspects of education at school level that prepare students to become active citizens by ensuring that they have the necessary knowledge, skills and attitudes to contribute to the development 
and well-being of the society in which they live" (Eurydice, 2011, p.10). This definition focuses on the value of knowledge and skills for creating a better society where they can live happily. Collado and Lopez (2006, p. 206) state that CE: "Can be understood as the knowledge, means, and activities designed to encourage students to participate actively in democratic life, accepting and exercising their rights and responsibilities." CE is immensely useful to make students or individuals aware of their rights and moral obligations and become a good citizen.

\section{HISTORY OF CE IN THE KSA}

$\mathrm{CE}$ in the KSA has passed through many stages (Alabdulkarim \& Alnassar, 2005; Alsalum, 1990). The first stage was between 1929 and 1936 which saw the emergence of citizenship education under the name of "Ethics and Citizenship Education". This education embodied family, nation, homeland, patriotism, government, government duty, types of government, constitution, individual rights, public authorities (legislative, executive, judicial) (Almalki, 2008) This course was taught an hour a week in grade three and two hours a week in grade four in primary schools. This course, however, was withdrawn from the curriculum after one year. Nevertheless, during that period of time, primary school education made people qualified to work in government as well as private sectors.

In 1930, the Ministry of Education changed the name to "Civic Information" to be taught once a week, to class 4 only, until 1936 including largely similar content in the curriculum. The second stage was from 1936 to 1984 . Over this period, citizenship education was absent from the education system. Alharbi (2010) attributed this absence to the different views of educators about the ability of these curricula to achieve the aims of citizenship education. They argued that the responsibility of achieving these aims lay with other curriculums, the school and social institutions. On the other hand, some researchers argued that the absence of citizenship education at that time was down to political concerns. The policy makers sought to isolate education from politics and to keep students away from all aspects of political activity, which was incompatible with citizenship education (Alsalum, 1990).

Between 1984 and 1990, citizenship education came back to the education system again. In this period there was a new education system which was known as "Developer Education". It was similar to the higher education system in that students could choose their subjects and make their individual timetables. Developer Education was introduced in secondary schools only and Citizenship Education in this system occupied two hours a week. The themes incorporated in the curriculum were the kings of the KSA, National Day, the flag of the country, loyalty to the king, defending the homeland, and the position of the KSA.

Unfortunately, the system was cancelled in 1990. The present stage began when the Ministry of Education decided to re-introduce citizenship education into the National Curriculum in the academic year 1997 as an independent subject in public schools, at all stages from fourth grade in primary school to the third grade in secondary school, for one class a week (Ministry of Education, 1997). Since 2010, in both the primary and intermediate stages, $\mathrm{CE}$ has become an integrated component of the Social Studies and Citizenship Education curriculum, which includes geography and history. At the secondary stage, the subject is taught separately, aiming mainly to prepare students to understand the national issues and their contribution towards their country (Alsharari, 2013). I next examine national identity of the KSA as this too affects the nature of the $\mathrm{CE}$ provided.

\section{CITIZENSHIP EDUCATION AND ISLAMIC VALUES IN THE KSA}

Education policy in the KSA asserts that "Religious education is compulsory in all years of primary, intermediate and secondary schools, and Islamic culture is a core subject in all years of higher education" (Ministry of Education, 1970, p. 3). Looking at the reading material in the textbooks of the Saudi public schools, one third is dominated by Islamic issues. For example, Religious Education makes up about a third of the elementary schools' curriculum and, if we include Arabic studies, they make up more than half of the curriculum. Similarly, more than a third of secondary schools' curriculum is religious education and Arabic studies together (Prokop, 2003). In addition, the main aim of the Saudi Arabian educational system is to consolidate Islamic values and "to aim the students in the true Islamic direction" (Ministry of Education 1970, p. 5). Saudi Arabia, as mentioned before, is an Islamic state where the Saudi constitution is based on the Holy Quran and Sunna (traditions of the prophet). The supremacy of these was stressed by the Basic Law of the country, issued in 1992: "The Kingdom of Saudi Arabia is an Arab, Islamic state; its religion is Islam and its constitution is the Holy Qur'an and the Sunnah (Prophetic sayings and deeds)" (Saudi Arabia Basic Law 1992, p. 2). For example, one of the components of the Holy Qur'an is advising peace for the world. Living together peacefully is moral and social virtue of every citizen. Likewise, being loyal is another virtue. It means citizens should remain faithful to their country and law. The Holy Qur'an also advises that, "o believers, be you securers of justice, witnesses for God" (Holy Qur'an $5 / 8$ ). Justice, equality and doing good for other people is important for a better society. In this sense, Islam has played a significant role in shaping its citizens' personal and national values and life. The teaching of the Holy Qur'an has certainly contributed to teaching CE in Saudi Arabian schools both directly and indirectly. Thus, teaching of Islamic values offers much background knowledge for supporting $\mathrm{CE}$ in Saudi Arabia. One aim of CE is "Implanting Islamic faith in the hearts of students, so that it guides their behaviour" and "Developing pride in belonging to the Islamic nation." More recently, Saudi Vision 2030, a much widely discussed document in Saudi Arabia, aims, "to embed positive moral beliefs in our children's characters from an early age by reshaping our academic and educational system" (p. 28). This will further endorse the value of CE to achieve the national goals of preparing better citizens who can live fulfilling lives and contribute to the nation building. Thus, one role of $\mathrm{CE}$ 
in the KSA is to maintain national identity which is Islamic identity. This appears in the goals of CE in Saudi education system.

\section{AIMS OF CE IN THE KSA}

Looking specifically at citizenship in the KSA, one of the important aims of education in the KSA is to "educate citizens to take part in building the nation, and teach responsibility to serve their country and defend it" (Ministry of Education 1970, p. 5). In addition, it aims at developing students' understanding of the problems of community (cultural, social, economic), and at preparing them to contribute to solutions. Given the importance of citizenship to this process, as noted above, the Ministry of Education re-introduced CE into the National Curriculum in 1997 as an independent subject in public schools, justifying it by the need to develop a national sense of belonging and identity, knowledge of society, values, attitudes, participation in community service, and knowledge of rights and duties, and prepare international citizens in accordance with circumstances and international developments. (Alrashid, 2004).

Based on these justifications, three levels of focus emerge. The first one concerned with national affiliation and Islamic identity. This was supported by the aims of CE. For example, the first and second aims emphasize the instilling Islamic faith in the hearts of students and promoting belongingness to the homeland and ensuring its security and stability by understanding the need to defend one's country. Moving to the second level, it focused on active participation of students by preparing them to become involved in society. This is mentioned in aim number 6 in general aims of CE "Introducing students to the characteristics and distinctive features of Saudi society" (Ministry of Education 1997, p. 2). The final level seeks to prepare students to be global citizens to respond to the changing world by preparing students to cope with this change (Alrashid, 2004). However, looking at the aims of $\mathrm{CE}$ in the KSA, it is interesting that there is no aim related to preparing students to be international citizen. In addition, the content of CE in the Kingdom of Saudi Arabia focuses on national level more than international as it is discussed later in the next section.

\section{CONTENT, TEACHING APPROACHES, AND PEDAGOGY OF CE IN THE KSA}

As noted above, CE was re-introduced as a compulsory subject at all educational phases: primary (7-12), intermediate (13-15) and secondary (16-18) in 1997. It is apparent from the aims of CE that it focuses on developing a sense of belongingness to the homeland and the security and stability of the country. Moreover, CE puts the emphasis on enhancing Islamic values so that pupils can understand their rights and obligations using the Islamic faith as a guideline. CE in the KSA, as Albdul Karim and Alnassar (2005) argue that aims to prepare students by developing their sense of belongingness to their country and taking pride in it. According to Almaamari (2009) CE is "intended to equip the student with basic historical and geographical information about their country, rights and responsibilities, the government and its institutions, and the role of the government in economic and social developments" (p. 66). With regard to the content of $\mathrm{CE}$ in the Kingdom, the material comprises the following topics:

- Geographical and historical information about the country (e.g. its location and history).

- Characteristics of the homeland (e.g. communications with the ruler and Islamic identity).

The role of government institutions.

Citizens' rights and duties.

The role of government in maintaining the environment.

- Law and order (e.g. implementation of Sharia law and respecting the law.

- Civic engagement and volunteering.

- Communication skills. (Almaamari, 2009, p. 67)

It is noted from the above topics that CE content in the Kingdom encourages sense of belonging to, and pride in, the homeland and Islamic religion. It can be seen that skills such as critical thinking and values and attitude received less attention in CE content. Along the same lines, the content also focuses on cultural, social and economic problems at the local and national level. In addition, it seeks to build a positive attitude towards work of any kind.

It is noticeable also that $\mathrm{CE}$ in the KSA focuses on national knowledge more than international and that there is little emphasis on skills and attitudes which is typical in many CE curricula such as EU countries, United States and North America (Faour \& Muasher, 2011). Hanivah (2000) maintains that $\mathrm{CE}$ content in the elementary school (ages 13 to 15) does not meet the students' needs in specific areas. For example, he notes that $\mathrm{CE}$ does not include topics about voluntary work and appropriate methods by which Saudi citizens can voice their opinions. Moreover, in terms of skills, $\mathrm{CE}$ does little to help students to improve their inquiry skills (being able to question and reflect on different ideas, analyse, interpret and evaluate different viewpoints). Problem solving skills, time management skills, and dialogue skills are also absent from $\mathrm{CE}$ at the elementary stage (Hanivah, 2000). In addition, students felt that cooperative working, problem solving skills, dialogue skills, information and communication technology skills were fundamental to become a good Saudi citizen (Alharbi, 2015). Further, Medina and Fernandez (2015, p.48) assert that CE emphasizes "citizenship's participation" in and outside the classroom encouraging students to prepare useful projects that can be used for the benefit of their community.

Lack of emphasis on global issues within CE in the KSA was noted by Aldubyan (2013) who reports that CE in Saudi Arabia does not address world and global issues such as the economy, the environment, climate change, emigration and terrorism. He believes this will result in pupils who feel isolated and different from the wider world, which may, in turn, have negative consequences, hindering their openness to others and other cultures around the world. Aligned with this argument, Almarshad (2015) asserts that, CE in the KSA does not address global issues especially that are related directly to Arab and gulf region. Moreover, Alharbi (2015) 
in his study found that participants did not receive enough about global issues and they thought that knowledge of international issues was important to Saudi students. The reason for this view was that they saw their country as part of the wider world, affecting and being affected by it. Faour and Muasher (2011) assert that "Young people today need to be both national and global citizens in order to expand their capacity to compete in an interdependent world and a globalized economy" (p.17). Students in this era need to be a part of "a global community and living in confidence in different communities around the world" (Ozbek, \& Susam, 2017, p. 804).

The reason for emphasis on national issues rather than international issues might refer to the aim of education system to make a strong affection among citizens so they will be pride in belonging to their country and willingness to sacrifice for the country. In his study Alharbi (2015) found that $\mathrm{CE}$ teachers believed that knowing about national issues helped to build social cohesion, to make society stronger and to confront any dangers coming from outside the country.

It is also important to explore how the content of CE is delivered. In other words, what is the pedagogy of CE in Saudi Arabia? According to Hanivah (2000), the lecture method is widely used by CE teachers to deliver CE in elementary schools as it does not require much preparation compared to other teaching methods in Saudi Arabia. Such result has been further validated by Almaamari (2009) study. He mentioned that "teachers, particularly in developing countries, tend to use traditional approaches to deliver CE" (Almaamari, 2009, p.105).

This method puts the teacher at the centre of the educational process, where learners are passive recipients who ask few or no questions in the classroom. Kizilbash (as cited in Dean, 2005, p. 47) argues that the traditional teaching method "is contributing to the socialization of obedient, passive citizens who lack critical thinking, questioning, decision-making and problem solving skills, who are closed minded followers rather than responsible and independent citizens".

One of the reasons why many teachers in the KSA use this method relates to the number of students in the classroom, as there are usually between 35 and 40 students. Al-Shimmari (2007) confirms that class size is one of challenges facing the introduction of non-traditional teaching methods in the KSA. Nwokocha and Osuji (2008: 9) argue that through the lecture approach "teachers can reach a large number of pupils at the same time; a large amount of materials can be covered in a short period of time". Other reason might refer to the lack of training. Alzamil $(2003$, p. 6) mention that most of CE teachers in the KSA "cling to tradition either because of their resistance to change or the limited knowledge and training they have received."

However, this method does not allow students to participate actively in learning and thus it does not promote skills of participation. Moreover, this approach is not necessarily appropriate for teaching concepts such as attitudes, feelings and values "which are not learned through pure telling" (Nwokocha \& Osuji, 2008, p. 12). CE has been seen to be effective where students are at the centre of the educational process through the use of active participation methods which encourage them to debate, question and participate (Huddleston \& Kerr, 2006). Teaching CE by giving students chances to participate in different kinds of activities such as writing reports and research on internet will make CE stronger than using the traditional teaching method. According to the Office for Standards in Education in the UK (Ofsted) (2010), keeping written records of students' work, including independent research using books, printed media and information and communication technology (ICT), were seen as very important in the schools where citizenship was strongest. Questions need to be asked, therefore, about whether such an approach to teaching is appropriate for the delivery of CE which involves discussion of attitudes and values as well as acquiring knowledge.

It is noteworthy that in the KSA the teacher is the centre of the education process and the approach is more passive. However, an appropriate pedagogy is not the only challenge facing $\mathrm{CE}$ in the KSA: there are other obstacles which will be discussed in the next section.

\section{DIFFICULTIES FACING CE IN THE KSA}

$\mathrm{CE}$ in Saudi Arabia, faces many challenges. From the above mentioned topics, it is clear that $\mathrm{CE}$ in the KSA emphasizes citizens' responsibilities, duties, identity formation, and obedience towards the system and how one can achieve these. It would appear that promoting freedom, equality, fairness, freedom of expression and participation in the decision making process is poorly addressed. According to Alsubaih (2005), the curriculum in the KSA is intended to emphasize citizens' duties and responsibilities and ways of fulfilling these, such as voluntary work, whereas equality, citizens' rights and ways of obtaining these, are minimally addressed. In addition, AlabdulKarim and Alnassar (2005) note that the content of $\mathrm{CE}$ in the KSA focuses on the national, i.e. citizenship within the boundaries of the country, and the role of students towards their country and community, while the courses are almost empty of any lessons which focus on matters that relate to world events and global issues. This view is supported by Almaitah's research (2011) on the citizenship curriculum from grade five in primary (age 12) to grade two in secondary (age 17). According to her analysis, symbols of the homeland dominate the curriculum, with active citizenship and participation in society being absent. According to Aldubyan (2013), CE has not exposed young people to the relationship between Islam and other religions or how to deal with non-Muslim people. He argues that this situation will lead to increasing intolerance and a lack of respect among students for those from other religions and cultures. Alanazi (2014) explored the views of 100 CE teachers about the challenges they meet in teaching Citizenship Education in secondary schools. They reported that more time and teaching aids were necessary to teach $\mathrm{CE}$ and the need for training on how to teach topics which are not related to their subject were major challenges they face.

A study conducted by Hanivah (2000) describes the reality of $\mathrm{CE}$ in the elementary stage. His research revealed that 
students were not motivated and that their satisfaction with the subject was moderate or less than moderate. The study concluded that repetition in the subject, lack of teaching aids and lack of specialist teachers were among the most common problems found in $\mathrm{CE}$ in the Arab world in general and the KSA in particular. According to Majed (1994, p. 2), the quality of CE in the Arab world:

remains dangerously low and the quality of civic education curricula, materials, and teaching techniques remain below the required standard. This weakness in civic education is impacting negatively on rising generations, who reach maturity without having received the information, skills, and behaviour patterns that would enable them to be productive and well integrated citizens. This threatens to slow the growth of civil society and may impede the process of democratisation in the region as a whole. What is needed is not only commitment to civic education and a more widespread application of it, but the development of curricula, materials, and techniques of civic education in order to render civic education more effective.

These observations from 1994 still hold and are in fact endorsed by (Aldubyan 2013; AlAbdulkarim \& Alnassar, 2005; Hanivah 2000). Insufficient training of teachers in the subject of citizenship is thus one of the shared problems in the Arab world, including the KSA. In his study, Alajaji (2002) pointed out the difficulties and challenges teachers face in teaching CE in secondary schools in KSA. He reported that insufficient training was a major difficulty and that the goals of CE were not clear, findings endorsed by AlAbdulkarim and Alnassar (2005) and Aldubyan (2013). Moreover, Alharbi (2015) in his study found that CE teachers were not specialists in citizenship education and most of them were geography and history teachers. They argue that they were not able to teach subjects related to CE such as human rights, climate change and terrorism.

Additionally, Almaitah (2011) argues that the CE curriculum needs to be reviewed by the Ministry of Education and that it needs to be supported and enriched by other subjects. $\mathrm{CE}$, she says, is only one element in achieving good citizenship and as such may not be able to achieve its purposes alone. Almalki (2008, p.49) endorses this, saying that "although citizenship education has been approved as a separate article in the education system in the Kingdom of Saudi Arabia, other educational curricula must have an active role in contributing to the field of citizenship education."

It is evident from the above discussion that $\mathrm{CE}$ in the KSA faces multiple challenges related to content, aims and teacher training. In addition, many authors note the danger of focusing on knowledge to the detriment of developing values, skills and a sense of active participation. In this context, Haste (2004, p. 435) argues that:

The knowledge model of citizenship education is not enough. It is through praxis, whether in the school or in the community, that the young person gains an identity as an active citizen, and the skills and efficacy to become one. A paradigmatic knowledge model, focusing on factual material about institutions, is unlikely to fire the imagination of the growing person.

\section{CONCLUSION}

This review of CE in Kingdom of Saudi Arabia, suggests the need for CE itself to be reviewed and for other subjects to play an active role and contribute to its development. In addition, In the Kingdom of Saudi Arabia, the focus is on how to build good citizens and ensure loyalty to the country whilst there is a lack on learning about democracy and human rights, alongside developing the skills of active participation. It seems that loyalty to the country and the security and stability of the country are fundamental because of the nature of Saudi context which consists of tribes with their own customs and territories. In addition, the emphasis on enhancing Islamic values was seen very important in Kingdom of Saudi Arabia as a result of the Islamic religion being an integral part of Saudi citizens' identity. However, the value of these subjects need to be accompanied by skills and values to build good Saudi citizen. What is needed is the sort of citizenship education that develops values, skills and a sense of active participation to the students. CE in the Kingdom of Saudi Arabia has its own principles because of the nature of the aims and Saudi context. However, the kingdom is facing changes in many levels related to contemporary challenges and international changes, suggesting further improvements in $\mathrm{CE}$ education to accommodate these change and challenges. It is necessary to take advantage of CE in other systems and countries to improve CE in the Kingdom of Saudi Arabia as it is part of the world and affected by international changes.

Moreover, CE in KSA suffers from many challenges such as repetition in the subject, lack of teaching aids and lack of specialist teachers. Moreover, the literature review showed that the lecture method is widely used by CE teachers to deliver $\mathrm{CE}$ in schools as it does not require much preparation compared to other teaching methods in Saudi Arabia.

To conclude, CE in the KSA need to be reviewed to meet the national goals as outlined in the Saudi Vision 2030 as well as to address the students' need in $21^{\text {st }}$ century. In addition, it warrants adequate in-service and pre-service teacher training to enable them to use different teaching methods which foster learners' active participation in CE rather than just the transmission of knowledge about CE. Further, the Ministry of Education would be advised to offer professional training courses to the teachers who come from other specializations to teach $\mathrm{CE}$ at schools to enhance their ability to teach $\mathrm{CE}$ in the future. Finally, the article informs an understanding of $\mathrm{CE}$ in the KSA in terms of content, approach and challenges which will contribute to building a clear picture of $\mathrm{CE}$ by the Ministry of Education in the KSA to achieve both Vision 2030 goals as well as to prepare national and global citizens.

\section{SUGGESTIONS FOR FURTHER RESEARCH}

This review of $\mathrm{CE}$ in the KSA highlighted the value of $\mathrm{CE}$ on the national level more than the global level. Therefore, I would recommend further research investigating relationships between national, regional and global themes and issues of CE. Findings may shed light on further improvement of CE making it relevant to students to enable them to realign themselves in the changing society and the world. Furthermore, 
this article identified lack of teaching aids and lack of specialist teachers and training as major challenges of teaching $\mathrm{CE}$ in the KSA. Further study may inform our understanding on how these contextual factors impact the overall quality of teaching and learning CE in the KSA. Finally, I recommend conducting a study investigating the methods and approaches to integrating a knowledge, skills, values and attitudes in CE that Saudi citizens need in the $21^{\text {st }}$ century.

\section{REFERENCES}

Alabdulkarim, R., \& Alnassar, S. (2005). Citizenship education in schools in Saudi Arabia: A comparative analysis in the light of modern educational trends. Paper presented at The $13^{\text {th }}$ Annual Meeting of the Educational Leaders, Albaha: Saudi Arabia.

ALajaji, A. (2002). Educational Difficulties Accompanying The Saudi Experience in Applying The National Education Syllabus, as secondary school teachers (Unpublished MA thesis). Faculty of Education: King Saud University, Saudi Arabia.

Alanzi, A. B. (2014). Third Intermediate Social and National Developed Textbook Evaluation from Teachers and Supervisors' Perceptions at Kingdom of Saudi Arabia (Unpublished MA thesis). Faculty of Education, Yarmouk University, Jordan.

Aldubyan, A. (2013). Papers in citizenship chalanges and problems, London: Dar ALhikma

Alessa, A. (2009). The development of moral values for students in elementary school in Al Qunfudhah (Unpublished MA thesis). Faculty of Education: Umm- Alqura university, Saudi Arabia.

Alhabib, F. (2010). Contemporary trends of teaching Citizenship Education. Retrieved 2 October 2016, from http://aafaqcenter.com/post/22.

Alharbi, B. (2015). The ability of Islamic Religious Education to deliver Citizenship Education in elementary schools in the Kingdom of Saudi Arabia (Unpublished doctoral thesis). Faculty of Education, Exeter University, England.

Alharbi, N. (2010). The role of citizenship education in support national belonging to the students in secondary school in Saudi Arabia (Unpublished MA thesis). Faculty of Education, Taibah University, Saudi Arabia.

Alhuqail, S. (1994). Education System and policy in Saudi Arabia ( $7^{\text {th }}$ ed.), Riyadh: Dar Alshebl

Aljazeera. (2011). 10\% unemployment rate in Saudi Arabia in 2010. Retrieved 11 October 2011, from http://www. aljazeera.net/ebusiness/pages/31 d65f56-b3da-40779d84-fa016315c7bb.

AlMaamari, S. (2009). Citizenship education in initial teacher education in the Sultanate of Oman: An exploratory study of the perceptions of student teachers of social studies and their tutors (Unpublished doctoral thesis). Faculty of Education, University of Glasgow, Scotland.

ALmaitah, R. (2011). Concepts of security awareness and build expertise in the general education curriculum, Paper presented at the Society and security King Fahd Security College: Saudi Arabia.
Almalki, A. (2008). The role of teaching citizenship education in the development of citizenship values among students in primary school, study from the viewpoint of teachers of citizenship education in the city of Alleth (Published doctoral thesis). Umm-Alqura University, Saudi Arabai.

Almarshad, Y. (2015). The development of Citizenship Education curriculum for first grade in secondary school in Saudi Arabia in light of some contemporary global challenges. The Journal of School of Education in Zagazig, 78(1), 73-124.

Alrashid, M. (2004). Our education to where. Riyadh: Al-Attar Press.

Alsalum, H. (1990). The history of development of education in the Kingdom of Saudi Arabia (3 ed.). Washington: international graphics.

Alsharari, L. (2013). Degree of inclusion of the concepts of traffic education in books of Social and Citizenship Education in primary school in Saudi Arabia (Unpublished MA thesis) Faculty of Education: Yarmouk University, Jordan.

Al-Shimmari, M. (2007). The problems of teaching the Koran in the primary grades (Unpublished MA thesis). Faculty of Education: King Saud University, Saudi Arabia.

Alsubaih, A. (2005). Secondary school students' view about citizenship and the role of some social institutions. Paper presented at the The thirteenth Annual Meeting of the Educational Leaders. AlBaha, Saudi Arabia.

Alzamil, O. (2003). High school Social Studies Teachers'attitudes and usage of Instructional Technology in Saudi Arabia (Unpublished doctoral thesis). Faculty of Education, University of Arkansas, the USA.

Collado, M., \& Atxurra, R. (2006). Democratic citizenship in textbooks in Spanish

Communications and Information Technology Commission, (CITC) (2013). Annual Report. Retrieved 20 August 2014, from http://www.citc.gov.sa.

Dean, B. (2005). Citizenship education in Pakistani schools: Problems and possibilities. International Journal of citizenship and Teacher education, 1(2), 35-55.

Eurydice. (2011). Citizenship education at school in Europe. Retrieved 15-09-2017, from http://www.eurydice.org

Faour, M., \& Muasher, M. (2011). Education for citizenship in the Arab world: Key to the future, Carnegie Endowment for International Peace.

Federation of Chambers of the Gulf Cooperation Council (GCC). (2007). Expats in Gulf countries. Retrieved 3 May 2015, from http:/www.fgccc.org/uploads/images/19628735091266128592.pdf.

Government of Saudi Arabia. (1992),). Basic Law of Government Riyadh: Government of Saudi Arabia. Retrieved 13 February 2014, from http://www.shura.gov.sa/wps/ wcm/connect/ShuraArabic/internet/Laws+and+Regulations/The + Basic + Law + Of + Government/The + Basic+Law+Of+Government/. Accessed 13 February 2014.

Hanivah, M. (2000). The reality of the national education curriculum in the intermediate stage in some cities of Saudi Arabia (Published doctoral thesis). Faculty of Education, Umm-Alqura University, Saudi Arabai. 
Haste, H. (2004). Constructing the citizen, Political Psychology, 25(3), 413-439.

Huddleston, T., \& Kerr, D. (2006). Making sense of citizenship. A continuing professional development handbook. London: Hodder Education.

Lee, W. (2004). Perceptions of citizenship qualities among Asian educational leaders', in W. Lee., D. Grossman, K. Kennedy and G. Fairbrother (eds.), Citizenship Education in Asia and the Pacific Concepts and Issues, CERC Studies in Comparative Education 14 (pp. 137 156), The Netherlands: Kluwer Academic Publishers Group.

Majed, Z. (1994). Civic Education in the Arab World organized, Paper presented at the Civic Education in the Arab World: Common Perspectives, Problems and Potential Cooperation, Lebanon.

Medina, E., \& Fernandez, N. (2015). Citizenship Education in the European Curricula. Procedia - Social and Behavioral Sciences, 197, 45 - 49.

Mellor, S., \& Prior, W. (2004). Promoting social tolerance and cohesion in the Solomon Islands and Vanuatu. In Citizenship Education in Asia and the Pacific, Netherlands: Springer.

Ministry of Education in the Kingdom of Saudi Arabia. (1970). Education policy in the Kingdom of Saudi Arabia, Ministry of Education.

Ministry of Education in the Kingdom of Saudi Arabia. (1997). Document of citizenship Education in General Education, Ministry of Education.

Mohammed Bin Rashid School of Government (MBRSG). (2014). Citizen Engagement and Public Services in the Arab World: The Potential of Social Media.', The Arab Social Midea report, Dubai.

Mokhtar, H. (2007). Contemporary issues and trends in curricula and teaching approaches, Makkah: Bahader printing press.
Nevo, J. (1998). Religion and national identity in Saudi Arabia. Middle Eastern Studies, 34(3), 34-53.

Nwokocha, N., \& Osuji, U. (2008). EDU 292 Primary education methods, National Open University of Nigeria.

Ochsenwald, W. (1981). Saudi Arabia and The Islamic Revival. International Journal of Middle East Studies, 13 (3), 271-286.

Ozbek, R., \& Susam, E. (2017). The evaluation of prospective teachers attitudes towards citizenship and citizenship education. Educational Research and Reviews, 12(16), 801-810.

Prokop, M. (2003). Saudi Arabia: the politics of education. International Affairs, 79(1), 77-89.

Qualifications and Curriculum Authority (QCA). (2007). Citizenship Programme of Study for Key Stage Three and Attainment Target. Retrieved 23 July 2013, from http:// curriculum.qca.org.uk/uploads/QCA-07-3329-pCitizenship3_tcm8-396.pdf?return=/key-stages-3-and-4/subjects/citizenship/keystage3/index.aspx\%3Freturn\%3D/ key-stages-3-and-4/subjects/citizenship/index.aspx.

The Office for Standards in Education in the UK. (Ofsted). (2010). Citizenship established? Citizenship in schools 2006/09. Manchester: Ofsted.

Vision 2030: Kingdom of Saudi Arabia. Retrieved 16 April 2017, from https:/www.google.com.sa/ search?rlz= 1C1CHMO_enSA 591SA591\& espv $=2 \& q=$ saudi+vision $+2030 \quad$ pdf\&oq=saudi + vision $+2030 \mathrm{pdf}$ \&gs_l=serp.3.0i13k1.7274.8164.0. 8949.3.3.0.0.0.0.2 54.473.2- 2.2.0.0.1c.1.64.serp.1.2.473.D EuxFmFpF5s.

Wilkins, C. (2003). Teachers and young citizens: teachers talk about their role as social educators. Westminster Studies in Education, 26(1), p 63-75.

UNESCO (1998) Citizenship Education for the $21^{\text {st }}$ Century. Retrieved: 15 October, 2017, from http:// www.unesco.org/education/tlsf/mods/theme_b/interact/ mod07task03/appendix.htm. 